JIPSINDO No. 2, Volume 2, September 2015

\title{
MAKNA BUDAYA LOKAL DALAM USAHA PENINGKATAN PENDAPATAN KELUARGA SEJAHTERA (UPPKS) (Studi Kasus Kelompok UPPKS di Kalimantan Tengah)
}

\author{
Roso Sugiyanto, Tatik Upami
}

Universitas Palangka Raya

email: rososugiyanto@gmail.com. Hp. 08562911030

\begin{abstract}
Abstrak
Penelitian ini bertujuan untuk menyelidiki: 1) Profil dan karakteristik UPPKS klaster di Kalimantan Tengah, dan 2) Partisipasi adat setempat di Kalimantan Tengah untuk eksistensi UPPKS. Populasi penelitian adalah semua kelompok UPPKS di Kalimantan Tengah, dan sampel yang cluster UPPKS di 6 kabupaten / kota. Hasil dari penelitian ini adalah sebagai berikut: 1) Pada tahun 2014 terdapat 216 UPPKS dengan 1852 anggota. Ada 11 cluster milik pertanian, 10 milik unggas, 9 milik perikanan, 6 milik kehutanan, 19 milik industri, 145 milik komersial, dan 37 milik industri jasa. 2) Nilai-nilai budaya lokal di Kalimantan Tengah yang berpartisipasi untuk eksistensi UPPKS adalah indeks daya jarak, individualisme vs kolektivisme, Indeks penghindaran ketidakpastian, maskulinitas vs feminitas, dan Orientasi jangka panjang.
\end{abstract}

Kata kunci: Budaya Lokal, UPPKS

\begin{abstract}
This study aims to investigate: 1) Profile and characteristic of UPPKS cluster in Central Kalimantan, and 2) The participation of local custom in Central Kalimantan for the existency of UPPKS. The research population were all UPPKS clusters in Central Kalimantan, and the sample were UPPKS clusters in 6 regencies/ city. The results of the study are as follows. 1) In 2014 there are 216 UPPKS with 1852 member. There are 11 clusters belong to farming, 10 belong to poultry, 9 belong to fishery, 6 belong to forestry, 19 belong to industry, 145 belong to commercial, and 37 belong to service industries. 2) The local cultural values in Central Kalimantan that participate for the existency of UPPKS are power distance index, individualism us collectivism, uncertainty avoidance index, masculinity us femininity, and Long-term Orientation.
\end{abstract}

Keywords: Local Culture, UPPKS 


\section{Pendahuluan}

Pembukaan Undang-Undang Dasar 1945 alinea ke-4 menyatakan bahwa Pemerintah Negara Indonesia bertujuan melindungi seluruh tumpah darah Indonesia, memajukan kesejahteraan umum dan mencerdaskan kehidupan bangsa. Untuk meningkatkan kesejahteraan diperlukan usaha-usaha ekonomis. Pemerintah dan masyarakat tidak dapat hanya mengandalkan usaha-usaha makro yang bertumpu pada investor/perusahaan besar. Masyarakat harus mampu bergerak di usaha mikro yang berbasis rumah tangga guna menciptakan lapangan kerja sendiri.

Undang-Undang No. 52 Tahun 2009 tentang Perkembangan Kependudukan dan Pembangunan Keluarga pasal 48 ayat 1 bagian (f) menyatakan bahwa salah satu cara melakukan kebijakan pembangunan keluarga dalam rangka peningkatan kesejahteraan keluarga adalah dengan meningkatkan peluang dan akses penerimaan sumber daya ekonomi melalui usaha mikro keluarga. Berdasarkan UU tersebut, Badan Kependudukan dan Keluarga Berancana nasional (BKKBN) sebagai salah satu instansi pemerintah yang menangani masalah kesejahteraan keluarga dalam kaitannya dengan peningkatan kualitas kependudukan juga menyadari pentingnya keberadaan usaha mikro yang dilakukan oleh keluarga Indonesia.

Usaha mikro berbasis rumah tangga merupakan wadah yang efektif guna meningkatkan kesertaan ber-KB masyarakat dalam rangka pengendalian kependudukan. Peran serta BKKBN dalam mendukung usaha mikro terwujud dalam pembentukan dan pembinaan kelompok-kelompok usaha yang dinamakan kelompok UPPKS (Usaha Peningkatan Pendapatan Keluarga 
Sejahtera). Tujuan utama kelompok UPPKS adalah meningkatkan pendapatan keluarga dan meningkatan kesertaan/kesinambungan ber-KB masyarakat, terutama penggunaan MKJP (Metode Kontrasepsi Jangka Panjang) (BKKBN, 2013).

Melihat peran UPPKS yang cukup strategis dalam pembangunan kesejahteraan keluarga Indonesia, dan juga melihat kondisi demografis provinsi Kalimantan Tengah saat ini yang cukup heterogen, maka menarik untuk melihat budaya yang menjadi sistem nilai bagi masyarakat di setiap Kabupaten. Masyarakat dayak, banjar, jawa, melayu dan berbagai suku lain menciptakan heterogenitas tersebut, tanpa ada suku yang begitu dominan secara mencolok. Heterogenitas suku ini pun melahirkan heterogenitas budaya lokal yang dapat mempengaruhi konsep masyarakat yang menganutnya dalam berusaha. Faktor inilah yang coba disorot oleh penelitian ini, untuk memberikan alternatif sudut pandang dalam mengkaji kelompok usaha mikro selain dari faktor-faktor produksi. Berdasarkan latar belakang yang telah dijelaskan di atas, maka penelitian ini perlu dilakukan untuk mengetahui:

1. Profil dan karakteristik kelompok UPPKS yang ada di Kalimantan Tengah,

2. Peran budaya lokal di Kalimantan Tengah dalam kelangsungan kelompok UPPKS.

\section{Makna Budaya Lokal}

Hofstede (1994) berpendapat bahwa the word culture is used here in the sense of the collective programming of the mind which distinguishes the members of one category of the people from another. Budaya mempunyai lima dimensi, dimensi yang pertama yaitu jarak kuasa (power distance index), yaitu variabel yang 
menggambarkan konsekuensi dari ketidakseimbangan kekuasaan dan hubungan otoritas (wewenang) dalam suatu masyarakat. Variabel ini mempengaruhi jenjang dan ketergantungan hubungan menurut konteks hubungan dan konteks organisasi. Lebih lanjut Hofstede (1994) menyatakan bahwa perilaku orang-orang pada situasi kerja sangat dipengaruhi oleh pengalaman awal di rumah dan di sekolah.

Dimensi budaya yang kedua adalah individualim $v s$ collectivism, yaitu "suatu tingkatan di mana individu-individu terintegrasi dalam kelompok" (Hofstede, (1994). Dalam masyarakat yang individualistis, ada penekanan pada kecakapan personal dan hak individual. Orang diharapkan berdiri atas kemampuan diri sendiri dan keluarga dekat. Orang juga diharapkan dapat memilih afiliasi mereka. Namun, hal sebaliknya terjadi pada masyarakat kolektivisme. Pada masyarakat kolektivisme, aktivitas individuindividu dipandang sebagai anggota kelompok sepanjang hidup dan kohesi sosial atau organisasi sangat diperlukan.

Dimensi budaya yang ketiga adalah menghindari ketidakpastian (uncertainty avoidance index), yaitu "toleransi masyarakat terhadap ketidakpastian dan perangkapan makna (ambiguity)". Hal ini mencerminkan tingkat usaha dan keinginan anggota masyarakat untuk mencoba mengurangi kejadian yang tidak diketahui dan keadaan luar biasa.

Dimensi kebudayaan yang keempat yaitu maskulinitas vs feminitas, yaitu "distribusi peran emosional antargender". Nilai Kultur maskulin adalah kompetitif, assertif, materialistis, dan memiliki ambisi serta kekuasaan yang tinggi. Sementara itu, kultur feminine lebih menempatkan nilai hubungan antar manusia dan kualitas hidup. Sebagai hasilnya, muncullah tabu 
pada seksualitas di beberapa negara, khususnya maskulinitas dan generalisasi gender.

Koentjaraningrat (1993) memperkenalkan beberapa istilah lain untuk merujuk kepada konsep yang disebut oleh Sarlito Wirawan sebagai profil kepribadian, atau etos oleh Benedict, atau kondisi psikokultural oleh Arief Budiman, atau the state of mind oleh Harrison. Istilah tersebut adalah nilai budaya atau sikap mental yang menjadi bagian dari faktor kultural.

Faktor kultural berarti hal ihwal yang berhubungan dengan kultur (budaya). Di sini budaya diartikan sebagai aturan-aturan yang mempengaruhi pola hubungan sosial antar individu atau antar kelompok. Aturan tersebut berbentuk abstrak dan dimiliki bersama oleh kelompok atau golongan. Yang termasuk dalam faktor kultural adalah mentalitas penduduk, adat istiadat, kepercayaan, etos kerja, nilai, pandangan, dan sebagainya (Marzali, 2007).

Dimensi kebudayaan yang kelima adalah orientasi jangka panjang versus orientasi jangka pendek. Menurut Hofstade, orientasi jangka panjang mengacu pada budaya yang berorientasi pada masa depan, dinamis, dan positif. Hal ini terkait dengan 4 pilar dasar konfisius antara lain ketekunan, hemat, rasa malu dan pengaturan. Orientasi jangka panjang mengacu pada individu yang berdedikasi, termotivasi, bertanggung jawab, dan berpendidikan dengan rasa komitmen dan identitas organisasi dan loyalitas yang tinggi.

Pemerintah dalam rangka membangun kesejahteraan masyarakatnya selalu berusaha untuk mendorong dan membantu masyarakat agar bisa terlepas dari kemiskinan. Upaya pemberdayaan masyarakat pra sejahtera untuk dapat mandiri, baik dalam pengertian ekonomi, budaya dan politik merupakan 
hakekat utama dalam penanggulangan kemiskinan. Kemampuan masyarakat untuk mewujudkan cita-cita agar hidup berkecukupan ditentukan dengan mengendalikan kemampuan yang dimilikinya, sehingga pemberdayaan (empowerment) merupakan jiwa partisipasi yang sifatnya aktif dan kreatif .

UPPKS merupakan kelompok kegiatan pendukung program KB yang anggotanya terdiri dari keluarga Pra-sejahtera dan Keluarga-sejahtera I, dalam rangka peningkatan kesejahteraan keluarga melalui kegiatan wirausaha (BKKBN, 2005). Kelompok yang dirintis oleh BKKBN pada tahun 1976 ini bertujuan untuk meningkatkan kondisi ekonomi keluarga perseta KB agar kehidupanya menjadi lebih sejahtera.

Salah satu hal yang mendasarinya adalah bahwa tanpa kondisi yang baik, kemungkinan kecil keluarga akan dapat meningkatkan kesejahteraanya, dan ini harus dimulai dari pemberdayaan keluarga di bidang ekonomi. Dengan demikian UPPKS ini diharapkan menjadi model usaha mikro keluarga yang berfungsi untuk menggerakkan roda ekonomi keluarga melalui pembelajaran di bidang ekonomi dengan cara menggugah minat dan semangat keluaga untuk berwirausaha (BKKBN, 2005).

\section{Metode Penelitian}

Penelitian ini menggunakan pendekatan penelitian kualitatif. Pada pendekatan ini, peneliti membuat suatu gambaran komplek, meneliti kata-kata, laporan terinci dari pandangan informan, dan melakukan studi kasus tentang peran budaya lokal di Kalimantan Tengah dalam kelangsungan kelompok UPPKS. Waktu penelitian bulan Oktober-Desember 2014, waktu pengumpulan data tanggal 9-20 Nopember 2014 dengan lokasi penelitian di 6 (enam) Kabupaten/Kota di Provinsi Kalimantan Tengah. Adapun nama- 
JIPSINDO No. 2, Volume 2, September 2015

nama kelompok yang menjadi sasaran penelitian adalah sebagai berikut:

Tabel 1. Kelompok UPPKS di 6 (enam) Kabupaten/Kota Di Provinsi Kalimantan Tengah

\begin{tabular}{|c|c|c|c|c|}
\hline \multicolumn{2}{|c|}{$\begin{array}{c}\text { Kabupaten/ } \\
\text { Kota }\end{array}$} & \multirow{2}{*}{\begin{tabular}{l}
\multicolumn{1}{c}{ Nama } \\
Kelompok/ \\
Nama Ketua \\
Hapakat/ \\
Ny. Enon \\
Umiati
\end{tabular}} & \multirow{2}{*}{$\begin{array}{l}\text { Jenis Usaha/ } \\
\text { Jumlah } \\
\text { Anggota }\end{array}$} & Alamat \\
\hline \multirow[t]{3}{*}{$\begin{array}{l}\text { Palang } \\
\text { ka } \\
\text { Raya }\end{array}$} & 1. & & & $\begin{array}{l}\text { J1. Tjilik Riwut } \\
\text { Gg. Pahlawan }\end{array}$ \\
\hline & 2. & $\begin{array}{l}\text { Boga Asri } \\
\text { (Aktif) } \\
\text { Hesty Dewi P. }\end{array}$ & $\begin{array}{l}\text { Industri } \\
\text { Rumah Tangga } \\
\text { / } 9 \text { orang }\end{array}$ & $\begin{array}{l}\text { Komplek } \\
\text { Bangas Permai, } \\
\text { Palangka Raya }\end{array}$ \\
\hline & 3. & $\begin{array}{l}\text { Ngudi Rahayu } \\
\text { / Sukiyem }\end{array}$ & $\begin{array}{l}\text { Pertanian / } 5 \\
\text { orang }\end{array}$ & $\begin{array}{l}\text { Kelurahan } \\
\text { Kalampangan, } \\
\text { Sabangau, } \\
\text { Palangka Raya }\end{array}$ \\
\hline \multirow[t]{2}{*}{ Kapuas } & 1. & Antik/ Santi & $\begin{array}{l}\text { Perdagangan } \\
5 \text { orang }\end{array}$ & $\begin{array}{l}\text { Kelurahan } \\
\text { Dahirang, } \\
\text { Kapuas Hilir, } \\
\text { Kapuas }\end{array}$ \\
\hline & 2. & $\begin{array}{l}\text { Sedap Malam } \\
\text { / Masliah }\end{array}$ & $\begin{array}{l}\text { Perdagangan } \\
10 \text { orang }\end{array}$ & $\begin{array}{l}\text { Handil } \\
\text { Panamas, Kec. } \\
\text { Selat, kapuas }\end{array}$ \\
\hline \multirow[t]{2}{*}{$\begin{array}{l}\text { Barito } \\
\text { Selatan }\end{array}$} & 1. & $\begin{array}{l}\text { Tut Wuri } \\
\text { Handayani / } \\
\text { Erika } \\
\text { Palentina }\end{array}$ & $\begin{array}{l}\text { Industri } \\
\text { Rumah } \\
\text { Tangga, } \\
\text { Peternakan, } \\
\text { Pertanian, } \\
\text { Jasa. } 10 \text { orang }\end{array}$ & $\begin{array}{l}\text { Desa/Keluraha } \\
\text { n Jelapat, } \\
\text { Dusun Selatan, } \\
\text { Barsel }\end{array}$ \\
\hline & 2. & $\begin{array}{l}\text { Usaha } \\
\text { Bersama }\end{array}$ & $\begin{array}{l}\text { Perdagangan / } \\
5 \text { orang }\end{array}$ & $\begin{array}{l}\text { Desa/Keluraha } \\
\text { n Hilir Sper, } \\
\text { Dusun Selatan, } \\
\text { Barsel }\end{array}$ \\
\hline \multirow[t]{2}{*}{$\begin{array}{l}\text { Barito } \\
\text { Utara }\end{array}$} & 1. & $\begin{array}{l}\text { Basukur } \\
\text { Sasama / } \\
\text { Jusarah }\end{array}$ & $\begin{array}{l}\text { Industri } \\
\text { Rumah Tangga } \\
20 \text { orang }\end{array}$ & $\begin{array}{l}\text { Kelurahan } \\
\text { Jambu, Kec. } \\
\text { Teweh Baru, } \\
\text { Barut }\end{array}$ \\
\hline & 2. & $\begin{array}{l}\text { Sinar Harapan } \\
\text { / Siti } \\
\text { Samsiah }\end{array}$ & $\begin{array}{l}\text { Industri } \\
\text { Rumah Tangga } \\
10 \text { orang }\end{array}$ & $\begin{array}{l}\text { Kelurahan } \\
\text { Jambu, Kec. } \\
\text { Teweh Baru, }\end{array}$ \\
\hline
\end{tabular}




\begin{tabular}{|l|l|l|l|l|}
\hline & & & & Barut \\
\hline $\begin{array}{l}\text { Kotawa } \\
\text { ringin } \\
\text { Timur }\end{array}$ & 1. & $\begin{array}{l}\text { Usaha Mandiri } \\
\text { / Sumarni }\end{array}$ & $\begin{array}{l}\text { Jasa, } \\
\text { Perdagangan } \\
18 \text { orang }\end{array}$ & $\begin{array}{l}\text { Kelurahan } \\
\text { Baamang Hilir, } \\
\text { Baamang, } \\
\text { Kotim }\end{array}$ \\
\cline { 2 - 5 } & 2. & $\begin{array}{l}\text { Rian Mentaya } \\
\text { / } \\
\text { Nina Novianti }\end{array}$ & $\begin{array}{l}\text { Perdagangan } \\
5 \text { orang }\end{array}$ & $\begin{array}{l}\text { Kelurahan } \\
\text { Baamang Hulu, } \\
\text { Baamang, } \\
\text { Kotim }\end{array}$ \\
\hline $\begin{array}{l}\text { Kotawa } \\
\text { ringin } \\
\text { Barat }\end{array}$ & 1. & $\begin{array}{l}\text { Sari Rasa / } \\
\text { Sarifah } \\
\text { Syalmah }\end{array}$ & $\begin{array}{l}\text { Industri } \\
\text { Rumah Tangga } \\
\text { 10 orang }\end{array}$ & $\begin{array}{l}\text { Jl. Swadaya } \\
\text { Desa Sungai } \\
\text { Kapitan, Kumai }\end{array}$ \\
\cline { 2 - 5 } & 2. & $\begin{array}{l}\text { Rezeki } \\
\text { Hj. Aslijah } \\
\text { Aban }\end{array}$ & orang & $\begin{array}{l}\text { J1. Malijo } \\
\text { RT.14, Kel. } \\
\text { Madurejo, Kec. } \\
\text { Arut Selatan }\end{array}$ \\
\hline
\end{tabular}

Sumber data diperoleh dari pernyataan yang diperoleh dari hasil wawancara dengan informan/subyek penelitian, dan data sekunder adalah data-data yang diperoleh dari bahan-bahan tertulis (buku catatan, tabel, jadwal, dan daftar). Pengumpulan data menggunakan metode observasi, wawancara, dan studi dokumentasi. Metode Pengolahan Data melalui tiga kegiatan analisis, yaitu reduksi data, penyajian data, dan menarik kesimpulan/verifikasi.

\section{Hasil Penelitian}

1. Karakteristik Kelompok UPPKS di Kalimantan Tengah

UPPKS dimulai sejak tahun 1979 melalui wadah UPPKA (Usaha Peningkatan Pendapatan Keluarga Akseptor) dalam rangka mewujudkan NKKBS (Norma Keluarga kecil Bahagia dan 
JIPSINDO No. 2, Volume 2, September 2015

Sejahtera). Sejak tahun 1994 UPPKA berkembang menjadi UPPKS (Usaha Peningkatan Pendapatan Keluarga Sejahtera). Sampai dengan saat ini kelompok UPPKS telah tersebar luas hingga ke seluruh pelosok tanah air.

Anggota kelompok UPPKS terdiri dari para peserta KB khususnya keluarga Pra Sejahtera dan KS I, maupun keluarga yang belum menjadi peserta $\mathrm{KB}$, termasuk peserta $\mathrm{KB}$ pria, maupun remaja serta anggota masyarakat di sekitarnya yang berminat untuk ikut mengembangkan kelompok UPPKS tersebut. Pada umumnya kegiatan yang dilakukan oleh kelompok UPPKS adalah upaya pemberdayaan ekonomi keluarga melalui berbagai usaha ekonomi produktif ataupun kegiatan simpan pinjam.

Berdasarkan faktor umur, anggota kelompok UPPKS di Kalimantan Tengah pada umumnya 57 persen responden merupakan wanita usia subur yaitu berusia $\leq 40$ tahun, sedangkan sisanya yaitu 43 persen merupakan wanita berusia > 40 tahun. Berikut secara rinci umur anggota Kelompok UPPKS di Kalimantan Tengah.

Tabel 2. Umur Informan anggota Kelompok UPPKS di Kalimantan Tengah

\begin{tabular}{|c|c|c|c|c|c|c|c|c|c|c|c|c|}
\hline \multirow{2}{*}{$\begin{array}{l}\text { Umur } \\
\text { responde } \\
\mathrm{n}\end{array}$} & \multicolumn{2}{|c|}{$\begin{array}{l}\text { Barito } \\
\text { Utara }\end{array}$} & \multicolumn{2}{|c|}{$\begin{array}{c}\text { Barito } \\
\text { Selatan }\end{array}$} & \multicolumn{2}{|c|}{$\begin{array}{l}\text { Kotw. } \\
\text { Timur }\end{array}$} & \multicolumn{2}{|c|}{$\begin{array}{c}\text { Kotaw. } \\
\text { Barat }\end{array}$} & \multicolumn{2}{|c|}{$\begin{array}{c}\text { Palangka } \\
\text { raya }\end{array}$} & \multicolumn{2}{|c|}{ Total } \\
\hline & $\mathrm{n}$ & $\%$ & $\mathrm{n}$ & $\%$ & $\mathrm{~N}$ & $\%$ & $\mathrm{n}$ & $\%$ & $\mathrm{n}$ & $\%$ & $\mathrm{n}$ & $\%$ \\
\hline $\begin{array}{l}\leq 40 \\
\text { tahun }\end{array}$ & 10 & 91 & 5 & 50 & 8 & 47 & 2 & 25 & 5 & 50 & 30 & 57 \\
\hline
\end{tabular}




\begin{tabular}{|l|l|l|l|l|l|l|l|l|l|l|l|l|}
\hline $\begin{array}{l}>40 \\
\text { tahun }\end{array}$ & 1 & 9 & 5 & 50 & 9 & 53 & 3 & 75 & 5 & 50 & 23 & 43 \\
\hline Jumlah & $\mathbf{1 1}$ & $\mathbf{1 0 0}$ & $\mathbf{1 0}$ & $\mathbf{1 0 0}$ & $\mathbf{1 7}$ & $\mathbf{1 0 0}$ & $\mathbf{5}$ & $\mathbf{1 0 0}$ & $\mathbf{1 0}$ & $\mathbf{1 0 0}$ & $\mathbf{5 3}$ & $\mathbf{1 0 0}$ \\
\hline
\end{tabular}

Berdasarkan jenjang pendidikan, secara umum jenjang pendidikan informan sudah cukup tinggi. Hal ini terlihat dari 38 persen responden yang tergolong berpendidikan tinggi (SMA atau lebih tinggi). Namun demikian, masih dijumpai pula responden yang hanya berpendidikan tamat SD (32 persen) dan tamat SLTP (30 persen).

Tabel 3. Jenjang Pendidikan Informan anggota Kelompok UPPKS di Kalimantan Tengah

\begin{tabular}{|c|c|c|c|c|c|c|c|c|c|c|c|c|}
\hline \multirow[t]{2}{*}{$\begin{array}{l}\text { Pendidikan } \\
\text { Responden }\end{array}$} & \multicolumn{2}{|c|}{$\begin{array}{l}\text { Barito } \\
\text { Utara }\end{array}$} & \multicolumn{2}{|c|}{$\begin{array}{l}\text { Barito } \\
\text { Selata } \\
\mathrm{n}\end{array}$} & \multicolumn{2}{|c|}{$\begin{array}{l}\text { Kotw. } \\
\text { Timur }\end{array}$} & \multicolumn{2}{|c|}{$\begin{array}{l}\text { Kotaw. } \\
\text { Barat }\end{array}$} & \multicolumn{2}{|c|}{$\begin{array}{l}\text { Palangk } \\
\text { a raya }\end{array}$} & \multicolumn{2}{|c|}{ Total } \\
\hline & $\mathrm{n}$ & $\%$ & $\mathrm{n}$ & $\%$ & $\mathrm{n}$ & $\%$ & $\mathrm{n}$ & $\%$ & $\mathrm{n}$ & $\%$ & $\mathrm{n}$ & $\%$ \\
\hline $\begin{array}{l}\text { Tidak tamat } \\
\text { SD }\end{array}$ & - & - & - & - & - & - & - & - & - & - & & \\
\hline Tamat SD & 6 & 55 & 2 & 20 & 5 & 29 & 3 & 75 & 1 & 10 & 17 & 32 \\
\hline Tamat SLTP & 3 & 27 & 1 & 10 & 8 & 47 & 2 & 25 & 2 & 20 & 16 & 30 \\
\hline $\begin{array}{l}\text { Tamat } \\
\text { SLTA+ }\end{array}$ & 2 & 18 & 7 & 70 & 4 & 24 & - & - & 7 & 70 & 20 & 38 \\
\hline Jumlah & 11 & $\begin{array}{l}10 \\
0\end{array}$ & 10 & $\begin{array}{l}10 \\
0\end{array}$ & 17 & $\begin{array}{l}10 \\
0\end{array}$ & 5 & 100 & 10 & $\begin{array}{l}10 \\
0\end{array}$ & 53 & $\begin{array}{l}10 \\
0\end{array}$ \\
\hline
\end{tabular}

Berikut adalah tabel status ber-KB Informan pada kelompok UPPKS di Kabupaten Barito Utara, Kabupaten Barito Selatan, Kabupaten Kotawaringin Timur, Kabupaten Kotawaringin Barat, dan Kota Palangka Raya.

Tabel 4. Status KB Informan (Anggota Kelompok UPPKS) 
JIPSINDO No. 2, Volume 2, September 2015

\begin{tabular}{|c|c|c|c|c|c|c|c|c|c|c|c|c|}
\hline \multirow{2}{*}{$\begin{array}{c}\text { Status } \\
\text { KB } \\
\text { Informa } \\
n\end{array}$} & \multicolumn{2}{|c|}{$\begin{array}{l}\text { Barito } \\
\text { Utara }\end{array}$} & \multicolumn{2}{|c|}{$\begin{array}{c}\text { Barito } \\
\text { Selatan }\end{array}$} & \multicolumn{2}{|c|}{$\begin{array}{l}\text { Kotw. } \\
\text { Timur }\end{array}$} & \multicolumn{2}{|c|}{$\begin{array}{c}\text { Kotaw. } \\
\text { Barat }\end{array}$} & \multicolumn{2}{|c|}{$\begin{array}{c}\text { Palangk } \\
\text { a raya }\end{array}$} & \multicolumn{2}{|c|}{ Total } \\
\hline & $\mathrm{n}$ & $\%$ & $\mathrm{n}$ & $\%$ & $\mathrm{n}$ & $\%$ & $\mathrm{n}$ & $\%$ & $\mathrm{n}$ & $\%$ & $\mathrm{n}$ & $\%$ \\
\hline $\mathrm{Ya}$ & 5 & 45 & 8 & 80 & 15 & 88 & 4 & 80 & 10 & 100 & 42 & 79 \\
\hline Tidak & 6 & 55 & 2 & 20 & 2 & 12 & 1 & 20 & 0 & - & 11 & 21 \\
\hline Jumlah & 11 & 100 & 10 & 100 & 17 & 100 & 5 & 100 & 100 & 100 & 53 & 100 \\
\hline
\end{tabular}

Dari tabel di atas, bisa dilihat bahwa kesertaan informan dalam ber-KB sudah cukup baik. Hal tersebut terlihat dari persentase total status $\mathrm{KB}$ informan yang cukup tinggi yaitu sebesar 79 persen.

Tabel di bawah ini adalah tabel jenis usaha dari masingmasing kelompok UPPKS yang ada di Kalimantan Tengah. Tabel tersebut memperlihatkan bahwa jenis usaha yang dilakukan dan dikelola pada umumnya adalah kegiatan dagang. Usaha berikutnya adalah di sektor lain-lain yang juga relative banyak dilakukan adalah usaha kerajinan.

Tabel 5. Jenis Usaha Kelompok UPPKS di Kalimantan Tengah

\begin{tabular}{|l|c|c|c|c|c|c|c|c|c|c|c|c|}
\hline \multirow{2}{*}{$\begin{array}{c}\text { Jenis } \\
\text { usaha } \\
\text { Informan }\end{array}$} & \multicolumn{2}{|c|}{$\begin{array}{c}\text { Barito } \\
\text { Utara }\end{array}$} & \multicolumn{2}{c|}{$\begin{array}{c}\text { Barito } \\
\text { Selatan }\end{array}$} & \multicolumn{2}{c|}{$\begin{array}{c}\text { Kotw. } \\
\text { Timur }\end{array}$} & \multicolumn{2}{c|}{$\begin{array}{c}\text { Kotw. } \\
\text { Barat }\end{array}$} & \multicolumn{2}{c|}{$\begin{array}{c}\text { Palangk } \\
\text { a raya }\end{array}$} & \multicolumn{2}{|c|}{ Total } \\
\cline { 2 - 16 } & $\mathrm{n}$ & $\%$ & $\mathrm{n}$ & $\%$ & $\mathrm{n}$ & $\%$ & $\mathrm{n}$ & $\%$ & $\mathrm{n}$ & $\%$ & $\mathrm{n}$ & $\%$ \\
\hline Dagang & 6 & 55 & 3 & 30 & 17 & 100 & - & - & - & - & 26 & 49 \\
\hline $\begin{array}{l}\text { Simpan } \\
\text { pinjam }\end{array}$ & - & - & - & - & - & - & - & - & - & - & - & - \\
\hline $\begin{array}{l}\text { Kerajina } \\
\mathrm{n}\end{array}$ & - & - & 3 & 30 & - & - & - & - & 5 & 50 & 8 & 15 \\
\hline $\begin{array}{l}\text { Menjahit } \\
\text { / border }\end{array}$ & 1 & 9 & - & - & - & - & - & - & - & - & 1 & 2 \\
\hline $\begin{array}{l}\text { Tambak } \\
\text { ikan }\end{array}$ & 1 & 9 & - & - & - & - & - & - & - & - & 1 & 2 \\
\hline
\end{tabular}




\begin{tabular}{|l|c|c|c|c|c|c|c|c|c|c|c|c|}
\hline $\begin{array}{l}\text { Kredit } \\
\text { Pakaian/ } \\
\text { alat } \\
\text { elektroni } \\
\mathrm{k}\end{array}$ & - & - & 2 & 20 & - & - & - & - & - & - & 2 & 4 \\
\hline $\begin{array}{l}\text { Perkebun } \\
\text { an }\end{array}$ & 2 & 18 & 2 & 20 & - & - & - & & - & - & 4 & 8 \\
\hline Lain-lain & 1 & 9 & - & - & - & - & 5 & 100 & 5 & 50 & 11 & 20 \\
\hline Jumlah & 11 & 100 & 10 & 100 & 17 & 100 & 5 & 100 & - & - & 53 & 100 \\
\hline
\end{tabular}

2. Peran Budaya Lokal dalam Kelangsungan UPPKS di Kalimantan Tengah

a. Power distance (jarak kuasa)

Power Distance berhubungan dengan bagaimana anggota UPPKS menerima kenyataan bahwa kekuasaan pada kelompoknya didistribusikan secara tidak sama. Hirarki menunjukkan bagaimana UPPKS mendistribusikan kekuasaan diantara anggotanya. Hasil pengamatan di lapangan UPPKS yang memiliki power distance tinggi, seperti di Kumai, Kotawaringin Barat kekuasaan didistribusikan secara sangat tidak sama. Ketua klompok UPPKS yang ada memiliki peran yang sangat penting dalam memanage kelompoknya.

Hal ini terlihat dimana ketua kelompok yang membagi bahkan menunjuk anggotanya untuk bekerja di bagian tertentu sesuai dengan kemampuannya berdasarkan penilaian secara subjektif seorang ketua. Ketika ada permasalahan dalam penghitungan, jumlah pesanan yang datang atau bahkan ketidakpahaman dalam bekerja, anggota kelompok pasti akan menghadap ke ketua. Begitu juga terkait dengan pembagian keuntungan yang diperoleh 
JIPSINDO No. 2, Volume 2, September 2015

kelompok UPPKS pembagiannya juga ditentukan berdasarkan kekuasaan yang dimiliki masing-masing anggota UPPKS. Perilaku yang ditunjukan salah satu UPPKS tersebut memperlihatkan kelompok yang berkuasa pada tingkat paling atas, maka pengambilan keputusan akan dilakukan secara sentralisasi dan menunjukkan adanya gaya kepemimpinan yang otokratik.

Sebaliknya dengan power distance yang rendah, maka hirarki sosial akan cenderung dilakukan dalam suatu gaya kepemimpinan yang konsultatif, dimana supervisi maupun bawahan bertindak interdependen, ini terdapat di sebagian besar UPPKS yang ada di Kalimantan Tengah. Pada kelompok ini terpengaruh budaya lokal yang pada awalnya kelompok UPPKS dibentuk dari kebiasaan usaha mereka yang dilakukan dari kegiatan sampingan yang dikerjakan sesudah ibu-ibu menyelesaiakan pekerjaan domestiknya. Misalnya kegiatan menganyam yang ada di masyarakat. kegiatan tersebut merupakan kegiatan sekedar untuk mencukupi kebutuhan sendiri (rumah tangga) bekerja sesusai dengan selera hati masing-masing karena hasilnya juga hanya untuk sendiri dan lingkungan sekitar tempat tinggal.

Dari hal tersebut maka tidak mudah untuk mengubah sistem tata nilai agar dapat berorientasai pasar yaitu bertujuan untuk mencari untung yang sebanyak-banyaknya. Pada UPPKS yang memiliki power distance yang tinggi, yakni salah satu kelompok 
yang ada di Kotawaringin Barat yang menunjukan power distance tinggi.

\section{b. Individualisme vs kolektivisme}

Masyarakat yang mempunyai budaya dengan tingkat individualism yang tinggi akan memberikan kebebasan personal dan otonomi kepada kepentingan individu. Sebaliknya masyarakat yang mempunyai budaya dengan tingkat collectivism yang tinggi, individu yang berada dalam suatu kelompok akan mementingkan kepentingan kelompok dan akan saling memperhatikan satu individu terhadap individu lainnya.

Bekerjasama dalam kelompok sudah lama dikenal masyarakat Kalimantan Tengah, istilah setempat "harubuh, hinjam, handep". Hal tersebut merpakan nilai-nilai lokal tentang arti kebersamaan untuk kegiatan produktif terutama saat menugal dan panen di ladang serta kegiatan sosial lainnya, seperti membuaat rumah dan acara kematian.

Hal ini artinya sejak lama sudah dikenal praktek bekerja sama dalam kelompok, dalam mengerjakan kegiatan ekonomi subsistem untuk mencukupi kebutuhan tanaga kerja saat mengerjakan ladang. Usaha ekonomi produktif sebenarnya sudah dikenal perempuan Dayak sejak lama, misalnya membantu 
JIPSINDO No. 2, Volume 2, September 2015

pekerjaan suami mengerjakan ladang, membuat alat rumah tangga untuk mencukupi kebutuhan sendiri, seperti tikar, bakul, lontoh/rambat serta alat pertanian lainnya. Masalah setiap rumah tangga dituntut untuk dapat mencukupi dan melengkapi kebutuhan sendiri, sehingga ada tuntutan secara tradisi bahwa perempan Dayak harus pandai mengayam rotan seperti tikar, serta peralatan rumah tangga lainnya dengan tujuan untuk dipakai sendiri (ekonomi sub sistem).

Keahlian ibu-ibu rumah tangga yang merupakan modal dasar untuk menambah penghasilan keluarga saat ini ditransformasikan dalam kegiatan anggota kelompok UPPKS yang ada di Kalimantan Tengah. Jadi sebenarnya UPPKS yang ada di Kalimantan Tengah dipengaruhi oleh budaya lokal yang ada. Untuk selanjutnya sistem evaluasi yang dirancang untuk melihat keberhasilan UPPKS yang ada dapat memperhatikan budaya yang mempengaruhi kehidupan anggota kelompok yakni mempunyai tingkat collectivism yang tinggi sehingga evaluasi keberhasilan UPPKS di Kalimantan Tengah dapat didasarkan pada pencapaian tujuan kelompok.

c. Uncertainty avoidance (Upaya menghindari ketidakpastian usaha). 
UPPKS di Kalimantan Tengah mempunyai budaya melakukan pengelakan ketidak pastian dengan tingkat rendah, hal ini terlihat pada prilaku anggota UPPKS, bahwa mereka:

1) Tidak berani mengambil resiko, tercermin dari untuk mengurangi resiko kerugian. Kegiatan prodksi berdasarkan pesanan.

2) Mereka menerima upah: bahan setengah jadi dari pengusaha lain, pembelian dan penjualan hasil dibayar secara tunai

3) Permodalan belum cukup.

d. Maskulinitas vs feminitas

UPPKS yang berada di Kalimantan Tengah secara umum termasuk dalam UPPKS yang memiliki budaya feminim. Mereka memberikan penghargaan kepada anggota karena rasa kerjasama dan rasa memiliki. Kerjasama dan rasa memiliki di antara anggota dalam UPPKS yang membawa kelompok mereka tetap aktif.

e. Orientasi masa depan.

Perilaku yang menunjukan orientasi masa depan dapat dilakukan dan sudah tercermin dalam kegiatan anggota kelompok UPPKS di beberapa daerah Kalimantan Tengah. Daerah tersebut seperti daerah Kapuas, Barito Selatan, Kotawarngin Barat, dan Kotawaringin Timur yang selalu berusaha untuk menginovasi produk agar dapat menyesuaikan zaman/permintaan pasar. 
JIPSINDO No. 2, Volume 2, September 2015

Kelompok yang jenis usahanya di bidang kerajinan daerah Kapuas, Barito Selatan dan Palangka Raya berusaha menginovasi produk yang dihasilkan. Mereka sudah dapat membuat inovasi/kreatifitas baru disesuakan dengan tuntutan zaman seperti, souvenir untuk acara perkawinan yang terbuat dari getah nyatu, tempat buah, tas map, 'i16 'jerbagai jenis tikar dari bahan baku rotan dengan berbagai ukuran dengan selera konsumen/pasar. Selain itu iuga seperti nampan dari kayu 116

dikreasikan dengan memberikan ornament kulit kayu meranti dan diberi hiasan anyaman rotan sehingga terlihat lebih menarik.

Kelebihan dari produk ini dibuat dengan handmade/ dibuat dengan tangan yang bersifat eksklusif. Daerah Sampit, Kabupaten Kotawaringin Timur anggota kelompok UPPKS jenis usahanya berdagang berinovasi dalam menghasilkan makanan ringan dari bahan baku pisang dan singkong yakni kripik dengan berbagai macam rasa, selain berjualan jamu tradisional. Di daerah Kumai Kotawaringin Barat mereka berinovasi untuk menghasilkan berbagai macam makanan ringan dari bahan baku ikan Tengiri.

\section{Simpulan}

Perkembangan kelompok UPPKS di Provinsi Kalimantan Tengah pada tahun 2014 berjumlah 216 kelompok dengan jumlah anggota 1852 orang dan anggota yang masih pasangan usia subur (PUS) sebanyak 1681 orang. Adapun jenis usaha dalam kelompok 
UPPKS adalah pertanian berjumlah 11 kelompok, peternakan berjumlah 10 kelompok, perikanan berjumlah 9 kelompok, kehutanan berjumlah 6 kelompok, industri berjumlah 19 kelompok, perdagangan berjumlah 145 kelompok dan jasa berjumlah 37 kelompok.

Kegiatan yang dilakukan oleh kelompok UPPKS adalah upaya pemberdayaan ekonomi keluarga melalui berbagai usaha ekonomi produktif ataupun kegiatan simpan pinjam. Kegiatan tersebut tidak lepas dari pengaruh kombinasi antara logika dengan nilai budaya lokal menurut Hofstade yang mempunyai lima dimensi. Pertama, jarak kuasa (power distance index/PDI). Kedua, individualisme vs kolektivisme (individualism/IDV vs collectivism). Ketiga, menghindari ketidakpastian (uncertainty avoidance index/UAI). Keempat, maskulinitas vs feminitas (masculinity (MAS) vs femininity). Kelima, orientasi jangka panjang (Long-term Orientation).

\section{Daftar Pustaka}

BKKBN. 2013. Buku Pedoman Pembinaan dan Pengembangan Ekonomi Keluarga melalui Kelompok UPPKS, Jakarta: Direktorat Pemberdayaan Ekonomi Keluarga Badan Keluarga Berencana Nasional.

Hardiyanto, 2009. Pengelolaan Usaha Kelompok, Jakarta : Direktorat Pemberdayaan Ekonomi Keluarga Badan Keluarga Berencana Nasional. 
JIPSINDO No. 2, Volume 2, September 2015

Hofstade, Gert Jan et al. (2002). Exploring Culture. Intercultural Press.

Hofstade, Gert (2011). Dimensionalizing cultures: The Hoftade Moel in Context dalam Larry Samovat et al Intercultural Communication: A Reader. Cengage Learning.

Moleong, Lexy J. 2007. Metodologi Penelitian Kualitatif, Bandung : PT Remaja Rosdakarya $\underset{118}{n f_{\sim}+}$

P.Robbins, Stephen; A, Judge Timothy. 2008. Organizational Behavior, 12th ed. (prilaku Organisasi, Edisi 12) buku 1. diterjemahkan oleh Diana, Ria dan Abdul. Jakarta: Salemba Empat.

Sugiyono, Dr, Prof. 2007. Metode Penelitian Kuantitatif Kualitatif dan R\&D. Bandung: Alfabeta.

Wycliffe Timotius Heryendi, dkk. 2003. Efektivitas Program Usaha Peningkatan Pendapatan Keluarga sejahtera (UPPKS) di Kecamatan Denpasar Barat. Jurnal ekonomi kuantitatif terapan Vol. 6 No. 2 agustus 2013 